\title{
Thereza Katinszky De Katina e PielesZ (I927-20I5)
}

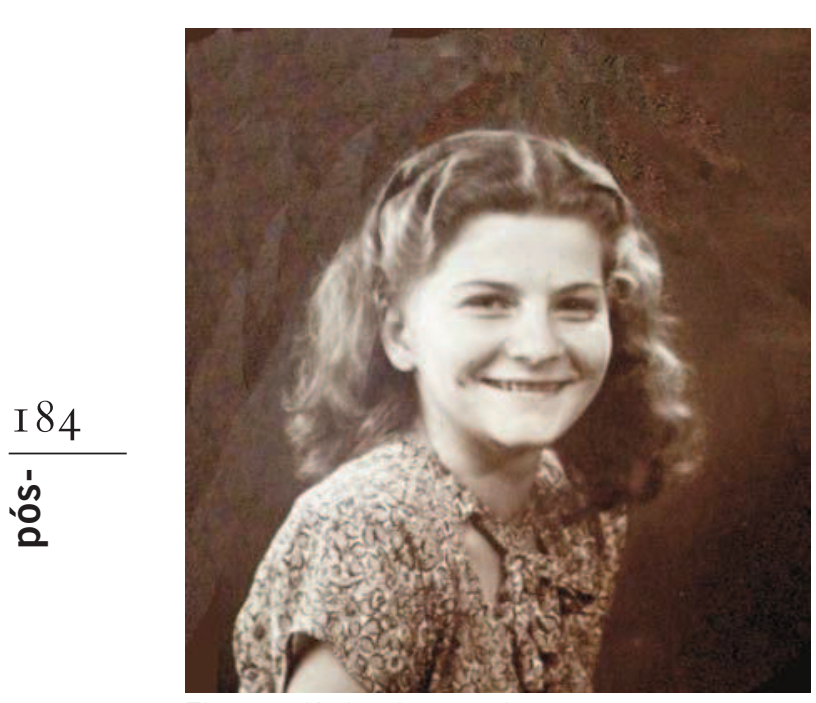

Thereza Katinszky, menina.

Foto: Acervo de Família

Júlio Roberto Katinsky
Arquiteta formada em 1952 pela Faculdade de Arquitetura e Urbanismo, iniciou seu aprendizado antes da fundação da sua Escola, pois junto com outros jovens com José Egreja, Ferrão, Marcílio Martins, Helio Pasta e outros, constituiu um grupo que insistiu junto aos senhores deputados da Assembleia Estadual para aprovar a lei de criação da nova Escola (que dependia de lei especial, naquele tempo), ocorrida nos últimos dias do primeiro semestre de 1948, a tempo de realizar-se o primeiro vestibular (que contou com mais três moças: Clementina Ambrosis, Natue Nomura, e Frejda Blinder). Thereza sentiu-se desde o primeiro instante com a convicção de estar fundando não uma Escola, mas uma profissão, pois, diferente da Capital da República que contava com Escola de Arquitetura desde 1824, a atividade de Arquiteto, em São Paulo, era exercida por arquitetos formados no exterior, como o próprio Ramos de Azevedo e Cristiano Stockler das Neves, ou estrangeiros como Ricardo Severo ou Victor Dubugras, havendo grande afluência de arquitetos alemães, franceses e italianos, ou mesmo o sueco Carlos Eckmann, autor do notável palacete de Antônio Álvares Penteado na avenida Higienópolis.

Eckmann deve ter impressionado fortemente a família Penteado, pois iria construir ainda a Escola de Comércio da mesma família em pleno Largo São Francisco, um dos mais veneráveis locais públicos da cidade, sede também, da não menos venerada, Faculdade de Direito da futura Universidade de São Paulo. Dois descendentes de Antônio Penteado, os irmãos Sylvio e Armando, decidiram doar o edifício da família para a Universidade de São Paulo, com a condição de fundar uma Escola de Arquitetura em 1947. Até então, havia cursos de arquitetura subordinados às Escolas de Engenharia da Politécnica de São Paulo e do Mackenzie College. Mas para a criação da Escola pesou também o êxito internacional da Arquitetura Moderna Brasileira com o edifício do Ministério da Educação e Saúde, com o Edifício Esther na Avenida Ipiranga, com o edifício da Estação de Hidros e o aeroporto Santos Dumont no Rio de Janeiro, entre outros, estes destacados por publicação em 1943 do Moma de Nova York. Também pela primeira vez, um arquiteto brasileiro (Oscar Niemeyer) era convidado para integrar a equipe que iria projetar o emblemático Edifício Sede da Organização das Nações Unidas em Nova York, em 1946-1948. 

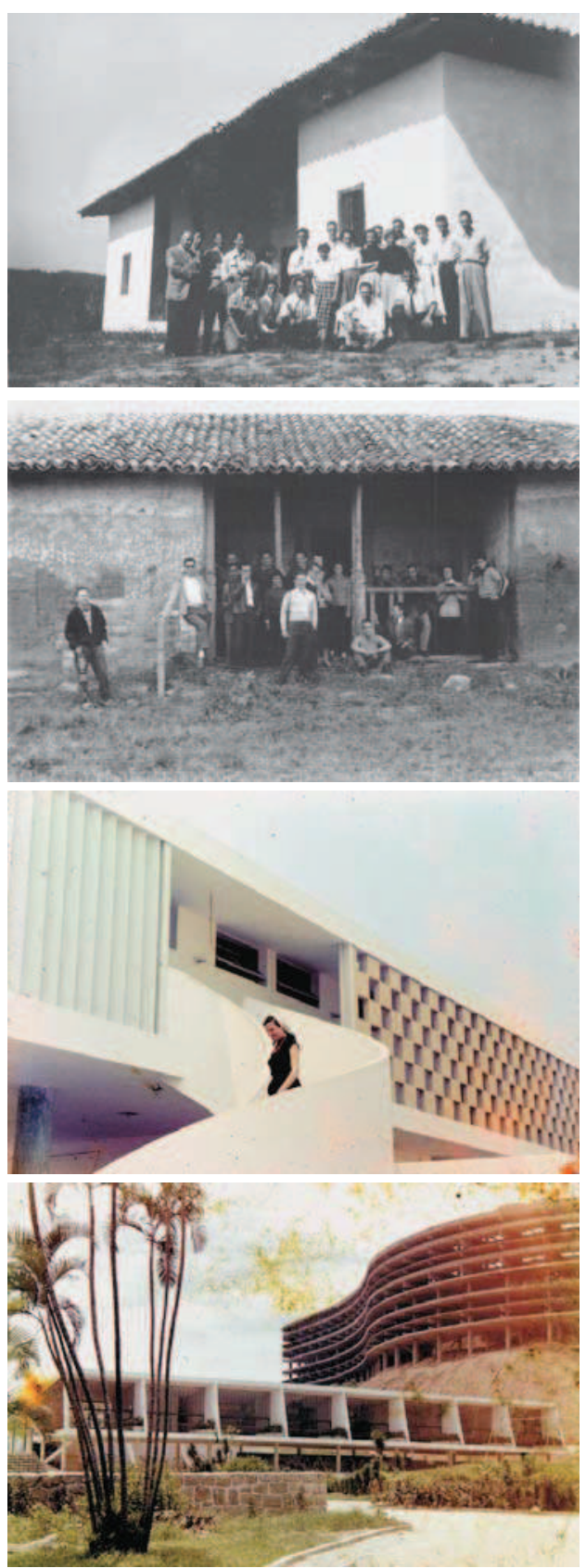

Mas não só na Escola Politécnica, desde a década de 20, dois engenheiros-arquitetos, Francisco Prestes Maia e Luís Anhaia Melo, destacaram-se em estudos e propostas urbanísticas caracterizando uma intensa pesquisa sobre o destino das cidades atuais. Justamente Luís Anhaia Melo, empenhou-se na fundação da nova Escola. Entretanto, do ponto de vista estrito da "estética" do projeto de edificação, quem mais se destacava, entre os arquitetos, era João Vilanova Artigas, autor de ícones paulistanos: o edifício Louveira (1946) e o Estádio do São Paulo F.C. (1951-1953). Se nós acrescentarmos os trabalhos do então Serviço do Patrimônio Histórico e Artístico Nacional, nós podemos ter uma ideia de quais foram as diretrizes arquiteturais que essa primeira turma e as imediatamente subsequentes absorveram na caracterização de seu trabalho profissional. Thereza Katinszky nos deixou um testemunho da programação e organização das viagens às cidades históricas, "como complemento às preocupações na sede da Escola com o patrimônio cultural brasileiro: Mas a viagem para Minas foi mais proveitosa do que a da Bahia, estávamos no terceiro ou quarto ano. Nós fomos para Belo Horizonte e fomos recebidos pelo Juscelino Kubitschek. Ele adorava arquitetos e todos os estudantes que iam lá ele hospedava nos melhores hotéis. Depois disso fomos para Ouro Preto, para Mariana foi um des/umbramento [.....] Agora, para Minas nós fomos de trem e de ônibus. E não fomos com professor, fomos com um funcionário da Reitoria, tinha que ter uma autoridade (entrevista concedida a João Sodré).

Após um estágio de um ano no escritório do arquiteto Franz Heep, participando do detalhamento de edifícios no centro de São Paulo e ainda da Igreja Matriz da Paróquia de São Domingos, nas Perdizes. Esse estágio marcou bastante a sua vida profissional. 0 arquiteto Heep era um homem interessado no progresso intelectual e profissional dos seus colaboradores. Segundo seu depoimento a Moracy Amaral, Thereza Katinszky passou todo ano de seu estágio detalhando completamente um edifício pequeno de uma sala, um banheiro e uma "kitinete" (pequena cozinha), cujo apelido na época era "J.K" (janela e kitinete), muito agradável e cuja construção ela acompanhou praticamente desde as fundações. Nessa época era muito ligada ao Convento dos Dominicanos e Frei Benevenuto de Santa Cruz pediu-Ihe para indicar alguém para projetar a Igreja Matriz. Assim, não só levou Heep para 

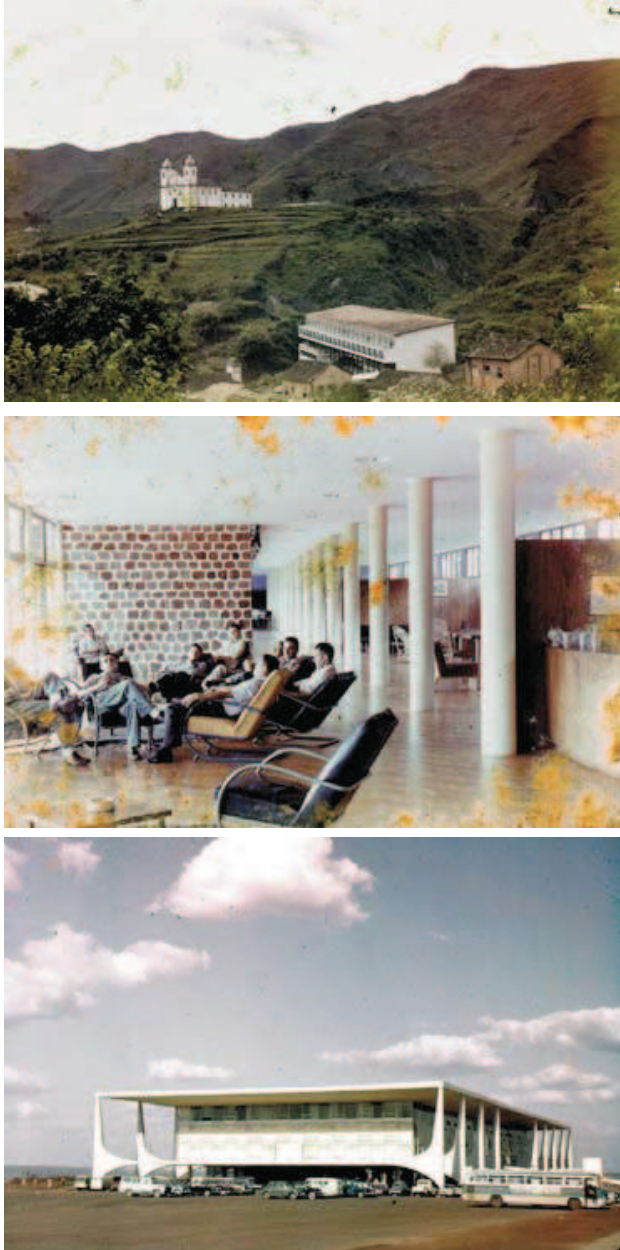

Fotos: Gustavo Neves da Rocha Filho (Acervo da FAUUSP),

Publicadas em Vila Penteado 1912-2012 - PósGraduação 40 Anos, FAUUSP, São Paulo, 2012. conhecer os dominicanos como aprendeu em sua formação de profissional, que é desenvolver um projeto em todos os seus detalhes por menores que sejam.. (segundo entrevista concedida a Moracy Amaral). Thereza Katinszky dedicou-se, desde que começou a trabalhar no Departamento de Obras Públicas (DOP), em projetos de edificações na capital e no interior do estado (inclusive creches na administração Montoro) e, depois de mais de um curso sobre Patrimônio, trabalhando no restauro dos bens culturalmente identificados, como por exemplo, o Recolhimento da Luz ou a Faculdade de Medicina da USP, ou no Condephaat do Estado (Conselho de defesa do Patrimônio Histórico, Artístico e Paisagístico do Estado de São Paulo) e no DPH (Departamento do Patrimônio Histórico) da Prefeitura do Município de São Paulo. Trabalhou também em Salvador, durante três anos a convite da arquiteta Adriana Castro como sua colaboradora em valiosas obras do patrimônio arquitetônico nacional.

A arquiteta Thereza Katinszky foi também representante da Conferência Nacional dos Bispos Brasileiros junto ao Conselho do Condephaat e participou do Icom (International Council of Museums). Pode-se, pois afirmar que junto com suas colegas da primeira turma, ela foi uma pessoa útil ao País, ao longo de mais de cinquenta anos de atividade.

\section{Obras consultadas:}

Almeida, Moracy Amaral e-Pilon, Heep, Korngold e Palanti - Edifícios de Escritórios (1930- 1960). SP FAU- Dissertação de mestrado-2015;

Katinsky, Júlio Roberto, Helena Aparecida Ayoub Silva e Sabrina Fontenelle Costa. Restauro da Faculdade de Medicina da USP, Estudos Projetos e Resultados. S.P. Medicina USP

Sodré, João Clark de Abreu, Arquitetura e Viagens de Formação pelo Brasil - 1938-1962. SP FAU Dissertação de mestrado 2010.

\section{Júlio Roberto Katinsky}

Professor Titular da FAUUSP e professor orientador no Programa de Pós-Graduação em Arquitetura e Urbanismo da USP

jrkatinsky@uol.com.br 